\title{
西双版纳望天树林土壤养分含量及其季节变化
}

\author{
薛敬意 唐建维 * 沙丽清 孟 盈 \\ (中国科学院西双版纳热带植物园热带雨林生态系统定位研究站, 云南预腊 666303)
}

摘 要 对西双版纳望天树 (Shorea chinensis) 林地 $0 \sim 10 \mathrm{~cm}$ 和 $10 \sim 25$ 土层的有机质, 全氮、磷、钾, 速效氮、磷、钾等 几种营养元素的含量状态及雨季前后的变化进行了研究。结果表明 :土壤的养分含量变化为旱季结束 $>$ 雨季结 束, 沟谷地带雨林>低山地带雨林, 并且差异显著; 表土 $0 \sim 10 \mathrm{~cm}$ 是养分富集区, $10 \mathrm{~cm}$ 以下土层的养分含量锐减, 两层养分含量对比, 除钾元素以外均差异显著, 表明望天树热带雨林生存的环境与植被的生活习性, 对土壤养分的 含量都有一定的影响。雨季对林地土壤的全钾和速效磷含量影响很大, 对有机质、全磷和速效钾的含量影响较小, 对氮素的影响是低山雨林 > 沟谷雨林。雨季期间土壤中的磷素消耗到严重缺乏的水平。

关键词 望天树林 土壤养分 西双版纳

\section{SOIL NUTRIENT CONTENTS AND THEIR CHARACTERISTICS OF SEASONAL CHANGES UNDER SHOREA CHINENSIS FOREST IN XISHUANGBANNA}

\author{
XUE Jing-Yi TANG Jian-Wei ${ }^{*}$ SHA Li-Qing and MENG Ying \\ ( Tropical Rainforest Ecosystem Station , Xishuangbanna Tropical Botanical Garden , the Chinese \\ Academy of Sciences, Mengla County, Yunnan Province 666303, China)
}

\begin{abstract}
Shorea chinensis forest of Xishuangbanna $\left(21^{\circ} 29^{\prime} \mathrm{N}, 101^{\circ} 34^{\prime} \mathrm{E}\right)$ is a rainforest type of tropical rainforest in South-east Asia entering into Xishuangbanna, which is significant in connecting with the flora of tropical rainforests in South-east Asia and elucidating characteristics of tropical rainforest in Xishuangbanna. In southern Mengla county , Xishuangbanna , Shorea chinensis forest grows on the mountain in altitude 700-900 $\mathrm{m}$, the soil is latosol, annual mean temperature is $21.1^{\circ} \mathrm{C}$, and annual mean precipitation is $1500-1600$ $\mathrm{mm}$. In order to know the soil nutrient content, organic matter, total N, P, K, available N , P, K and their seasonal changes under Shorea chinensis forest in Xishuangbanna, we took soil samples in the top soil (0-10 $\mathrm{cm})$ and under the top soil $(10-25 \mathrm{~cm})$ from 47 plots among 10 different patches of Shorea chinensis forest in May and November , 1999. 23 plots were located in valleys and 24 plots in lower mountainous areas. The results showed there are obvious difference in the soil nutrient content in different soil layers, in different seasons and in different areas : 1) in different soil layers, nutrients were rich in the top soil $(0-10 \mathrm{~cm})$ and poor under $10 \mathrm{~cm}$ depth. The content of nutrients under $10 \mathrm{~cm}$ depth was about $56 \%-75 \%$ of the nutrients in top soil ; available P content was only $0.039 \%$ of the nutrients in top soil. 2) Soil nutrient content changes with seasons ; nutrients were higher before the rainy season than after the rainy season. The content of organic matter , total $\mathrm{N}$, total $\mathrm{P}$ and total $\mathrm{K}$ in top soil after rainy season was $94 \%, 90 \%, 94 \%$ and $82 \%$ of the content before rainy season respectively, and the content of available $\mathrm{N}$ and available $\mathrm{K}$ in top soil after rainy season was $89 \%, 92 \%$ of the content before rainy season. Available P decreased sharply in top soil after rainy season ; the content of available $\mathrm{P}$ in top soil after the rainy season was only $0.078 \%$ of the content before the rainy season. The change in nutrient content under top soil after rainy season was the same as the change in nutrient content in top soil. 3) Concerning soil nutrient content in different area, nutrients were also higher in valleys than in lower mountainous areas. The content of organic matter, total $\mathrm{N}$, total $\mathrm{P}$ and total $\mathrm{K}$ in top soil in lower mountainous area were $79 \%, 80 \%, 84 \%$ and $83 \%$ of the content in valley respectively, while the content of available $\mathrm{N}$, available $\mathrm{P}$ and available $\mathrm{K}$ were also lower in top soil in lower mountainous area than in valleys.

From the above results, we can conclude that seasonal changes significantly affected total $\mathrm{K}$ and available $\mathrm{P}$, but only slightly affected total $\mathrm{P}$, available $\mathrm{K}$ and organic matter, and affected $\mathrm{N}$ content more in lower mountainous areas than in valleys. In the rainy season $\mathrm{P}$ content in soil is very poor. The environment and plant growth rhythm of Shorea chinensis forest have some effects on the soil nutrient content.
\end{abstract}

Key words Shorea chinensis forest, Soil nutrients , Xishuangbanna 
西双版纳的望天树林 (Shorea chinensis forest, SCF) 以龙脑香科植物望天树为上层优势树种，它作 为东南亚嵌入热带北缘的雨林类型，在连接东南亚 热带雨林植物区系以及在阐明西双版纳热带雨林的 性质和特点上具有特别重要的意义(朱华,1992)。 近年来由于人类生产经济活动的日益加剧, 西双版 纳的原始森林受到剧烈的破坏, 作为我国一级保护 的稀有植物望天树并以之为上层优势种的望天树林 也惨遭同样的厄运，目前的望天树林以大小不一的 16 个斑块呈破碎的条状和块片状残存分布在预腊 县东南部 6 条河谷的两侧 (朱华,1992) ,因受破碎化 栖息地生境的影响, 使得该类森林群落的面积与数 量都很小。到目前为止, 部分学者已对望天树的形 态特征(朱华,1992)、种群的动态 (赵学农等,1990) 和种子萌发(殷寿华等, 1990) 及其群落的区系组成 (朱华,1992)、林窗小气候变化(刘文杰等,2000)等 方面进行了研究。但对林地土壤养分的含量及季节 变化的研究工作还未见报道。本文在这一方面进行 初步研究, 对今后深入研究望天树群落的养分循环、 生存环境及其保护工作均具有一定的意义。

\section{1 试验区概况与研究方法}

\section{1 研究林地自然环境}

西双版纳预腊县自然保护区位于北纬 $21^{\circ} 29^{\prime}$, 东经 $101^{\circ} 34^{\prime}$ 。这里的年平均降雨量为 $1500 \sim 1600$ $\mathrm{mm}$, 主要分布在 5 月下旬～10 月的雨季(占 $83 \%$ ), 11 月～翌年 4 月为旱季(占 $17 \%$ ), 但是旱季期间林 地几乎每天都有大雾、重露, 部分弥补了雨量的不 足。全年平均相对湿度为 $87 \%$,年平均温度 21 . $1{ }^{\circ} \mathrm{C}$, 最冷月 (1月)和最热月 (5 月) 的平均气温分别 为 $15.7^{\circ} \mathrm{C}$ 和 $24.6^{\circ} \mathrm{C}$ 。与世界热带雨林分布的主要 地区相比, 本地区的降雨量偏少, 干、湿季明显, 气候 偏干，热量偏低(张克映,1963)。

在西双版纳，望天树林分布于预腊县境内南部， 海拔 $700 \sim 900 \mathrm{~m}$ 之间的山地, 土壤为砖红壤 (Latosol) , 群落结构较为复杂, 乔木层可分为 4 层, 上层优势种几乎全为望天树组成, 高 $40 \sim 60 \mathrm{~m}$, 林 冠不连续, 郁闭度约为 0.4 ; 中层主要树种有番龙眼 (Pometia tomentosa)、千果榄仁 (Terminalia myriocarpa)、大叶白颜树 ( Gironniera subaequalis)、小叶藤黄 (Garcinia cowa) 等等, 高 $20 \sim 30 \mathrm{~m}$, 有闭度为 0.5 左 右; 第三层主要为三桠果 (Baccaurea ramiflora)、第四 层以假海桐 (Pittosporopsis kerri) 等占优势, 高 $6 \sim 20$ $\mathrm{m}$, 郁闭度约为 0.3 ; 灌木层是由大量的乔木幼树和
少量的灌木个体组成，一般低于 $5 \mathrm{~m}$; 草本层则随地 形、地势的不同 种类的组成及其覆盖度呈现不同的 变化, 通常以柊叶 (Phrynium capitatum) 、虾膜花 ( $A$ canthus leucostachyus) 为常见(朱华,1992)。在望天树 林分布的范围内有众多的小河支流地形以低山、丘 陵为主。低山望天树雨林样地 (以下简称低山雨林) 主要位于补蚌村附近, 是由断断续续的不同斑块联 成一体的较大面积的低山原始林地, 在大面积低山 林区内还存在着面积大小不等、分布无规律的农垦 地。另外在离低山望天树林西部约 $10 \mathrm{~km}$ 的广纳里 村至景飘的南杭河流域两侧也有望天树群落, 分布 在已经开发利用地区中的沟谷地带, 形成狭长的走 廊状沟谷林带, 生境光照较少, 地形狭窄坡度较大, 谷口方向基本朝南, 是残留的片段化沟谷地带原始 林 (以下简称沟谷雨林)。本试验的土壤取自 10 个 面积大小不同的望天树雨林斑块的 47 块样地, 可代 表望天树群落在本地区不同生境中的土壤养分含量 状况。

\section{2 土样的采集}

在广纳里至景飘直线距离约 $10 \mathrm{~km}$ 的 5 个沟谷 林带中 根据地形分别选定了具有代表性的望天树 群落样地 $3 \sim 6$ 个, 共 23 个试验点。

在补蚌地区近 $20 \mathrm{~km}^{2}$ 的低山雨林地中，根据地 理位置和地势确定 5 个试验区并各自选定具有代表 性的望天树群落样地 3 6 个 共 24 个试验点。

土样的采集分别于 1999 年的 5 月和 11 月进 行 根据不同斑块面积的大小, 在每个斑块中挖取 3 $\sim 5$ 个剖面 按 $0 \sim 10 \mathrm{~cm}, 10 \sim 25 \mathrm{~cm}$ 分层采土(以下 分别简称上层、下层)，土样按测试项目的要求风干、 磨碎过筛、装瓶供室内测试。

\section{3 分析项目与方法}

分析项目为土壤有机质、全氮、全磷、全钾和速 效的氮、磷、钾等。测定方法: 有机质用重铬酸钾外 热法; 全氮用开氏法; 磷用 $\mathrm{HCl}-\mathrm{HF}$ 消化钼锑抗比色 法, 钾用原子吸收分光光度计法, 速效氮用碱解扩散 法, 速效钾用乙酸铵浸提法, 速效磷用 Bray1 法 ; pH: $\mathrm{H}_{2} \mathrm{O}$ 为 5:1 电位法; 壤水分为烘干称重法, 土壤容 重为环刀法。

\section{2 结果与分析}

\section{1 旱季结束时林地土壤的主要养分含量分布} 根据望天树林地的分布情况, 把沟谷地带和低 山地区的试验分别进行统计分析 结果如表 1 所示, 低山雨林表土层 $(0 \sim 10 \mathrm{~cm})$ 的有机质和全氮、全 
磷、全钾的含量以及有效态的氮、磷、钾含量均小于 沟谷雨林:有机质和全氮、全磷、全钾的含量分别是 沟谷雨林的 $79 \% 、 80 \% 、 84 \%$ 和 $83 \%$; 有效态的氮、 磷、钾含量分别是沟谷雨林的 $90 \% 、 54 \%$ 和 $83 \%$ 。 进行 $t$-检验, 低山雨林土壤有机质和全氮含量极显 著地小于沟谷雨林, 全钾和有效性磷显著地小于沟 谷雨林。

下层土壤 $(10 \sim 25 \mathrm{~cm})$ 的有机质含量、氮、磷、 钾的全含量与有效态含量, 低山雨林也同样底于沟 谷雨林, 有机质含量约是沟谷雨林 $67 \%$ 。氮、磷、钾 的全含量与有效态含量分别为沟谷雨林的 $74 \%$ 、 $78 \% 、 89 \%$ 和 $93 \% 、 50 \% 、 93 \%$ 。低山雨林土壤养分 含量除了有效态氮和钾略低于沟谷雨林以外,其余 均低于沟谷雨林较多,有效磷仅为沟谷林的 $1 / 2$ 。 进行 $t$-差异检验, 低山雨林土壤有机质、全氮的含量 极显著地小于沟谷雨林, 全磷和有效性磷则显著地 小于沟谷雨林。

下层土壤中除全钾的含量略高于表土外，其它 养分均为表土层含量较高。下层土壤与表土层相 比，有机质、全氮、全磷和有效态的氮、磷、钾含量下 降幅度很大:沟谷雨林分别为 $61 \% 、 68 \% 、 82 \%$ 和 $61 \% 、 26 \% 、 64 \%$,低山雨林则为 $53 \% 、 63 \% 、 76 \%$ 和 $64 \% 、 24 \% 、 71 \%$ 。有效态磷仅为上层土壤含量的 $1 /$ 4。经 $T$ 值进行差异检验，土壤上、下层养分含量分 布差异明显, 沟谷雨林和低山雨林差异呈极显著水 平的是土壤有机质、全氮、有效性的氮和磷。不同的
是, 沟谷雨林的有效性钾也呈极显著的差异, 低山雨 林地则是全磷的含量具有显著的差异。

\section{2 雨季结束后土壤的养分含量分布}

雨季结束后, 望天树雨林土壤的养分含量减少 (表 2)，上层土壤有机质含量平均为 $3.358 \%$, 是旱 季结束的 $95 \%$ 。沟谷雨林为 $3.805 \%$, 低山雨林为 $3.034 \%$, 是沟谷雨林的 $80 \%$ 。两者雨季结束与旱季 结束时的相对比例关系较稳定。氮、磷、钾的土壤全 量为: 低山雨林分别是沟谷雨林的 $80 \%$ 、82\% 和 $75 \%$,与旱季结束相比, 全钾含量的差异增大。土壤 中有效性的氮、磷、钾含量为: 低山雨林分别是沟谷 雨林的 $88 \% 、 60 \%$ 和 $113 \%$,而低山雨林的有效性磷 含量则下降到小于 $5 \mathrm{mg} \mathrm{kg}^{-1}$ 的严重贫瘦水平(孙波 等,1995)。这一时期，低山雨林与沟谷雨林地的土 壤养分含量差异, $t$-检验结果为:土壤有机质、全氮、 全钾达到极显著水平, 全磷和有效氮达到显著水平。 与旱季结束相比，全磷、全钾和有效氮的差异增大， 有效性磷的差异减小。

下层土壤 $(10 \sim 25 \mathrm{~cm})$ 有机质含量，低山雨林 低于沟谷雨林, 沟谷雨林为 $2.310 \%$,低山雨林为 $1.668 \%$, 是沟谷雨林的 $72 \%$ 。雨季结束与旱季结束 时，两者土壤有机质含量比率相对稳定。土壤中氮、 磷、钾的全量,沟谷雨林为 $0.143 \%$ 、0.036 $5 \%$ 、 $1.240 \%$ ，低山雨林为 $0.118 \% 、 0.0279 \% 、 0.832 \%$ ， 分别是沟谷雨林的 $82 \% 、 76 \%$ 和 $67 \%$,低山雨林下 层土壤的养分含量与沟谷雨林的相比, $t$-检验结果

表 1 旱季结束望天树林土壤养分的平均含量 (5 月)

Table 1 The nutrient contents in soil under SCF in the end of dry season (May)

\begin{tabular}{|c|c|c|c|c|c|c|c|c|}
\hline & $\begin{array}{c}\text { 土层深度 } \\
\text { Soil depth }(\mathrm{cm})\end{array}$ & $\begin{array}{l}\text { O.M } \\
(\%)\end{array}$ & $\begin{array}{l}\mathrm{N} \\
(\%)\end{array}$ & $\begin{array}{l}\mathrm{P} \\
(\%)\end{array}$ & $\begin{array}{c}\mathrm{K} \\
(\%)\end{array}$ & $\begin{array}{c}\text { A.N } \\
\left(\mathrm{mg} \mathrm{kg}^{-1}\right)\end{array}$ & $\begin{array}{c}\text { A.P } \\
\left(\mathrm{mg} \mathrm{kg}^{-1}\right)\end{array}$ & $\begin{array}{c}\text { A. K } \\
\left(\mathrm{mg} \mathrm{kg}^{-1}\right)\end{array}$ \\
\hline \multicolumn{9}{|l|}{ 沟谷 In valley $(N=23)$} \\
\hline 平均 Mean & $0 \sim 10$ & 4.073 & 0.230 & 0.045 & 1.309 & 250.333 & 18.887 & 181.989 \\
\hline 标准偏差 Standard deviation & & 1.059 & 0.051 & 0.011 & 0.277 & 50.605 & 16.337 & 67.373 \\
\hline 变异系数 Coefficient of variation & & 0.26 & 0.22 & 0.25 & 0.21 & 0.20 & 0.86 & 0.37 \\
\hline 平均 Mean & $10 \sim 25$ & 2.476 & 0.157 & 0.037 & 1.331 & 153.901 & 5.020 & 116.596 \\
\hline 标准偏差 Standard deviation & & 0.827 & 0.031 & 0.012 & 0.359 & 48.279 & 4.091 & 39.434 \\
\hline 变异系数 Coefficient of variation & & 0.33 & 0.20 & 0.32 & 0.27 & 0.31 & 0.81 & 0.34 \\
\hline$t$-检验 $T$-test & & $5.0442^{* *}$ & $5.2143^{* *}$ & 1.9668 & 0.0224 & $5.8497^{* *}$ & $3.2988^{* *}$ & $3.3761^{* *}$ \\
\hline \multicolumn{9}{|c|}{ 低山 In lower mountainous area $(N=24)$} \\
\hline 平均 Mean & $0 \sim 10$ & 3.212 & 0.185 & 0.038 & 1.093 & 224.632 & 10.285 & 151.588 \\
\hline 标准偏差 Standard deviation & & 0.744 & 0.037 & 0.013 & 0.318 & 41.637 & 6.167 & 83.715 \\
\hline 变异系数 Coefficient of variation & & 0.23 & 0.20 & 0.36 & 0.29 & 0.19 & 0.60 & 0.55 \\
\hline 平均 Mean & $10 \sim 25$ & 1.663 & 0.117 & 0.029 & 1.186 & 143.907 & 2.504 & 108.052 \\
\hline 标准偏差 Standard deviation & & 0.450 & 0.020 & 0.009 & 0.321 & 31.796 & 0.322 & 69.280 \\
\hline 变异系数 Coefficient of variation & & 0.27 & 0.18 & 0.31 & 0.27 & 0.22 & 0.13 & 0.64 \\
\hline$t$-检验 $t$-test & & 6.5887 & 9.6345 & 2.5000 & $<1$ & 6.8906 & 5.4291 & 1.7917 \\
\hline
\end{tabular}

$* * t_{0.01}=2.704 * t_{0.05}=2.021\left(n_{1}+n_{2}-2\right)>40$

O.M : 有机质 Organic matter A.N : 有效性氮 Available nitrogen A.P : 有效性磷 Available phosphorous A.K : 有效性钾 Available potassium 
表明:土壤有机质、全氮、全磷、全钾和有效性氮、都具 有极显著的差异。与旱季结束相比, 低山雨林下层 土壤的全钾、全磷和有效性氮的含量与沟谷雨林之 间的差异增大, 土壤的速效磷含量差异减小。与表 层土壤的变动基本一致。

雨季结束后土壤上、下两层的养分分布差异依 然存在, 与旱季结束时相比, 沟谷雨林的变化为: 有 效性磷和钾的含量从 $t$-检验的极显著差异变为显著 的差异，其差异减小；低山雨林的全磷含量从 $t$-检验 的显著差异变为极显著的差异，其差异增大。

\section{3 雨季对望天树林地土壤养分变化的影响}

到目前为止, 对森林土壤养分的季节动态变化 研究报道不多, 这可能是元素在土壤内的季节性变 化幅度较小及其分布差异无一定规律性的原因。本 文的研究结果表明西双版纳望天树林地土壤中有些 养分季节性变化是很明显的。表 3 为旱季结束和雨 季结束后, 望天树林表层土壤 $(0 \sim 10 \mathrm{~cm})$ 的养分含 量状况。根据红壤林地土壤养分的标准(孙波等, $1995)$, 速效磷含量旱季结束时为轻度贫痊 (10 15 $\left.\mathrm{mg} \mathrm{kg}^{-1}\right)$, 雨季结束后为中度贫瘠 $(5 \sim 10 \mathrm{mg}$ $\left.\mathrm{kg}^{-1}\right)$ 。与海南省的雨林土壤的养分含量相比:高于 海南雨林的有机质 $(2.45 \%)$ 、全磷 $(0.014 \%)$ 和有效 性的氮 $\left(135 \mathrm{mg} \mathrm{kg}^{-1}\right)$ 、磷 $\left(4.55 \mathrm{mg} \mathrm{kg} \mathrm{kg}^{-1}\right)$ 、钾 $(10 \sim$ $80 \mathrm{mg} \mathrm{kg}{ }^{-1}$ ); 低于海南的全钾 $(2.23 \%$ ) 含量 (赵其 国等, 1991)。望天树雨林在雨季结束后, 林地土壤
的养分都有不同程度的减少, 土壤有机质及氮、磷、 钾的全量, 分别是旱季结束的 $95 \% 、 91 \% 、 95 \%$ 和 $83 \%$, 其中全钾的减少幅度较大, 有机质和全磷的含 量相对稳定, 有效态的氮、钾为旱季结束时的 $90 \%$ 和 $91 \%$, 而有效态磷仅为 $53 \%$, 减少幅度最大。 $t$ 检验的结果为:雨季结束与旱季结束时，土壤中养分 含量有显著差异的是全氮和有效性氮, 具有极显著 差异的是全钾和有效性磷。

2.4 雨季结束与旱季结束时土壤养分的分布差异 比较

表 4 为望天树雨林雨季结束与旱季结束时土壤 养分含量的比值。结果表明 经过一个雨季后, 沟谷 雨林土壤养分都有减少的趋势。而低山雨林除去有 效态钾呈上升趋势以外，其它的养分都有不同程度 的减少。根据土壤养分在雨季结束与旱季结束时的 含量对比, 其差异的 $t$-检验结果表明, 沟谷雨林土壤 养分含量差异显著的为:表土层 $(0 \sim 10 \mathrm{~cm})$ 的全 钾、有效性磷和钾，而下层土壤 $(10 \sim 25 \mathrm{~cm})$ 养分的 差异不明显; 低山雨林土壤养分含量差异极显著的 为 :表土层的有效性磷和下层土壤的全钾; 差异显著 的为 表土层的全氮、全钾和有效性的氮。总体上林 地的土壤表层养分下降幅度的顺序为有效态磷 > 全 钾 $>$ 有效态氮 $>$ 全氮 $>$ 有机质 $>$ 全磷。雨季对低山 雨林土壤的养分影响大于沟谷雨林, 对表土层 $(0 \sim$ $10 \mathrm{~cm})$ 的影响大于下层土壤 $(10 \sim 25 \mathrm{~cm})$ 。

表 2 雨季结束望天树林地土壤的养分含量(11月)

Table 2 Nutrient contents in soils under SCF at the end of rainy season (Nov.)

\begin{tabular}{|c|c|c|c|c|c|c|c|c|}
\hline & $\begin{array}{c}\text { 土层深度 } \\
\text { Soil depth }(\mathrm{cm})\end{array}$ & $\begin{array}{l}\text { O.M } \\
(\%)\end{array}$ & $\begin{array}{l}\mathrm{N} \\
(\%)\end{array}$ & $\begin{array}{l}\mathrm{P} \\
(\%)\end{array}$ & $\begin{array}{l}\mathrm{K} \\
(\%)\end{array}$ & $\begin{array}{c}\text { A.N } \\
\left(\mathrm{mg} \mathrm{kg}^{-1}\right)\end{array}$ & $\begin{array}{c}\text { A.P } \\
\left(\mathrm{mg} \mathrm{kg}^{-1}\right)\end{array}$ & $\begin{array}{c}\text { A.K } \\
\left(\mathrm{mg} \mathrm{kg}{ }^{-1}\right)\end{array}$ \\
\hline \multicolumn{9}{|l|}{ 沟谷 In valley $(N=23)$} \\
\hline 平均 Mean & $0 \sim 10$ & 3.805 & 0.207 & 0.043 & 1.123 & 224.667 & 9.388 & 143.889 \\
\hline 标准偏差 Standard deviation & & 1.117 & 0.042 & 0.014 & 0.320 & 40.185 & 9.129 & 41.682 \\
\hline 变异系数 Coefficient of variation & & 0.29 & 0.20 & 0.32 & 0.17 & 0.18 & 0.97 & 0.29 \\
\hline 平均 Mean & $10 \sim 25$ & 2.310 & 0.143 & 0.0365 & 1.240 & 153.327 & 3.747 & 112.606 \\
\hline 标准偏差 Standard deviation & & 0.685 & 0.027 & 0.013 & 0.239 & 30.228 & 2.920 & 41.764 \\
\hline 变异系数 Coefficient of variation & & 0.30 & 0.19 & 0.36 & 0.19 & 0.20 & 0.78 & 0.37 \\
\hline$t$-检验 $t$-test & & $5.6266^{* *}$ & $5.2143^{* *}$ & 1.6291 & $<1$ & $6.9512^{* *}$ & $2.8452^{* *}$ & $2.6260^{*}$ \\
\hline \multicolumn{9}{|c|}{ 低山 In lower mountainous area $(N=24)$} \\
\hline 平均 Mean & $0 \sim 10$ & 3.034 & 0.167 & 0.0352 & 0.845 & 198.724 & 5.610 & 162.198 \\
\hline 标准偏差 Standard deviation & & 0.722 & 0.029 & 0.006 & 0.216 & 38.479 & 2.216 & 91.418 \\
\hline 变异系数 Coefficient of variation & & 0.24 & 0.17 & 0.18 & 0.26 & 0.19 & 0.39 & 0.56 \\
\hline 平均 Mean & $10 \sim 25$ & 1.668 & 0.118 & 0.0279 & 0.832 & 122.622 & 2.267 & 115.534 \\
\hline 标准偏差 Standard deviation & & 0.482 & 0.022 & 0.003 & 0.213 & 29.218 & 1.05 & 67.534 \\
\hline 变异系数 Coefficient of variation & & 0.29 & 0.19 & 0.11 & 0.26 & 0.24 & 0.46 & 0.58 \\
\hline$t$-检验 $t$-test & & $6.0617^{* *}$ & $5.2575^{* *}$ & $4.8121^{* *}$ & $<1$ & $6.8658^{* *}$ & $3.7614^{* *}$ & 1.5471 \\
\hline
\end{tabular}

$* * t_{0.01}=2.704 * t_{0.05}=2.021,\left(n_{1}+n_{2}-2\right)>40 \quad$ O.M , A.N , A.P , A.K : 同表 1 See Table 1 
表 3 望天树林表土 $(0 \sim 10 \mathrm{~cm})$ 养分的平均含量对比 $(N=47)$

Table 3 The nutrient contents in $0-10 \mathrm{~cm}$ soil under SCF $(N=47)$

\begin{tabular}{|c|c|c|c|c|c|c|c|}
\hline & $\begin{array}{l}\text { O.M } \\
(\%)\end{array}$ & $\begin{array}{c}N \\
(\%)\end{array}$ & $\begin{array}{c}\mathrm{P} \\
(\%)\end{array}$ & $\begin{array}{c}\mathrm{K} \\
(\%)\end{array}$ & $\begin{array}{c}\text { A.N } \\
\left(\mathrm{mg} \mathrm{kg}^{-1}\right)\end{array}$ & $\begin{array}{c}\text { A.P } \\
\left(\mathrm{mg} \mathrm{kg}^{-1}\right)\end{array}$ & $\begin{array}{c}\text { A.K } \\
\left(\mathrm{mg} \mathrm{kg}^{-1}\right)\end{array}$ \\
\hline \multicolumn{8}{|c|}{ 旱季结束 (5 月) At the end of dry season (May) } \\
\hline 平均 Mean & 3.528 & 0.202 & 0.041 & 1.195 & 236.81 & 14.359 & 165.99 \\
\hline 标准偏差 Standard deviation & 0.954 & 0.047 & 0.013 & 0.315 & 47.29 & 12.695 & 76.95 \\
\hline 变异系数 Coefficient of variation & 0.27 & 0.23 & 0.31 & 0.26 & 0.20 & 0.88 & 0.46 \\
\hline \multicolumn{8}{|c|}{ 雨季结束(11月)At the end of rainy season (Nov.) } \\
\hline 平均 Mean & 3.358 & 0.184 & 0.039 & 0.995 & 212.56 & 7.625 & 152.43 \\
\hline 标准偏差 Standard deviation & 0.979 & 0.04 & 0.012 & 0.247 & 41.09 & 7.03 & 69.23 \\
\hline 变异系数 Coefficient of variation & 0.29 & 0.22 & 0.30 & 0.25 & 0.19 & 0.92 & 0.45 \\
\hline$t$-检验 $t$-test & 0.9069 & $2.1363^{*}$ & 0.7367 & $3.242^{* *}$ & $2.4999^{*}$ & $3.0494^{* *}$ & 0.8448 \\
\hline
\end{tabular}

$* * t_{0.01}=2.704 \quad * t_{0.05}=2.021,\left(n_{1}+n_{2}-2\right)>40 \quad$ O.M , A.N , A.P , A.K : 同表 1 See Table 1

表 4 林地土壤养分含量雨季结束与旱季结束时的比率

Table 4 Ratio of soil nutrient contents in SCF compared in the end of rainy season with those in the end of dry season

雨季结束 $(11$ 月 $) /$ 旱季结束 $(5$ 月)

In the end of rainy season (Nov.)/in the end of dry season (May)

沟谷 In valley $(N=23)$

$0 \sim 10 \mathrm{~cm}$

$10 \sim 25 \mathrm{~cm}$

低山 In lower mountainous areas $(N=24)$

$0 \sim 10 \mathrm{~cm}$

$10 \sim 25 \mathrm{~cm}$

O.M

$\mathrm{N}$

$\mathrm{P}$

K

A.N A.P

A. K

\begin{tabular}{ccccccc}
0.93 & 0.90 & 0.96 & $0.86^{*}$ & 0.90 & $0.50^{*}$ & $0.77^{*}$ \\
0.93 & 0.91 & 0.98 & 0.93 & 0.99 & 0.75 & 0.97 \\
& & & & & & \\
0.94 & $0.90 *$ & 0.92 & $0.77^{*}$ & $0.88^{*}$ & $0.54^{* *}$ & 1.07 \\
1.01 & 0.92 & 0.96 & $0.70^{* *}$ & 0.85 & 0.90 & 1.07 \\
\hline
\end{tabular}

$* * t_{0.01}=2.704 \quad * t_{0.05}=2.021,\left(n_{1}+n_{2}-2\right)>40 \quad$ O.M , A.N , A.P , A.K : 同表 1 See Table 1

\section{3 讨 论}

1)西双版纳以望天树为上层优势种的热带雨林 经过长期的演替, 形成本地区的一种结构复杂、物种 多样性丰富并且相对稳定的顶极森林生态系统。明 显的干湿季分布, 较高的森林覆盖度, 林下高温、高 湿的小气候，促进了土壤中的生物活动，使该类森林 具有雨季前后养分的差异与生物、气候条件变化同 步的特点。作为养分归还主要途径之一的调落物， 每年返回到土壤中的调落物达 $11.56 \mathrm{t} \mathrm{hm}^{-2}$, 接近 世界热带雨林平均调落物量 $\left(6 \sim 12 \mathrm{t} \mathrm{hm}^{-2}\right)$ 最大 值(郑征等,2000)。其凋落高峰具有突出明显和持 续时间较长的特点 3 月和 4 月的凋落量最大，分别 为 $2.63 \mathrm{t} \mathrm{hm}$ 和 $2.83 \mathrm{t} \mathrm{hm}^{-2}$, 约占年凋落量的 $23.4 \%$ 和 $25.1 \%$ (郑征等，1990），为雨季期间土壤养 分的强烈交换提供了物质基础。在雨季, 不仅土壤 中的水分含量增加，而且气温较高，使植物生长发育 旺盛，而水热条件是生物活性及养分迁移的基础，从 而导致土壤养分的消耗量 > 累积量; 而旱季期间，则 是土壤养分的累积量 > 消耗量，与何园球等 (1993) 在海南省吊罗山对雨林的研究结果相一致。雨季期 间, 望天树林的土壤全钾和全磷的含量大幅度减少， 表明养分的供求矛盾仍然存在。Foth (1978) 认为：
质含量年年都维持恒定, 土壤中的循环氮量保持大 体恒定”。在对氧化土壤的养分研究中表明“: 强度 风化的砖红壤表现更为明显，不仅仅是钾素淋失，而 且土壤溶液中只能维持极低的磷素平衡浓度, 下层 土壤比上层更加明显, 说明了调落物是植被有效养 分的重要来源, 这时林木扎根很深从风化度较浅的 深层土壤中吸取养分, 同时依靠广布土壤上层的根 系吸收调落物矿化释放出的养分”。由于该类森林 肥沃土壤层极薄, 导致土层 $0 \sim 10 \mathrm{~cm}$ 与 $10 \sim 25 \mathrm{~cm}$ 的养分含量, 在统计上具有极显著差异。表明望天 树雨林较薄的表土层养分富集明显, 并且养分的含 量变化大于下层。林地表土受生物作用影响, 系统 内快速、强烈的养分分解-吸收-补充是其肥力保持 稳定的主要机制。

2)虽然在沟谷雨林周围唇区不断扩大的情况 下，生境破碎化程度远大于低山雨林的生境，但是雨 林强烈的养分运动在沟谷的天然屏障中得到一定程 度的保护, 减缓了气候变化引起的生态系统与大气 候的水热交流，这一点得益于 西双版纳的静风、热 量和雨量有效性高的气候特点” (张克映,1963)。因 此沟谷雨林受大气候的影响小于低山雨林, 水汽和 热量与大气的交换也小于低山雨林，晴好天气时，沟 谷内的湿度大于低山地带, 间接地促使沟谷雨林的 蒸腾量小于低山雨林, 导致植被从土壤中吸收养分 
而产生差异。植物的蒸腾作用受到湿热向空气输送 的通量影响 (牛文元,1981)。Foth (1978) 认为“: 许 多热带土壤粘土含量高, 并有较多的无定形粘土 , 其 结果是有效地保护了有机质, 使之免遭分解。” 同时 他还指出“: 一个地区的土壤粘粒含量和有机质含量 之间, 存在着相关性。较多地联合供应水和养分, 有 利于在较细质地的土壤中生产和积累更多的有机 质。粘粒还吸附具有分解力的酶, 使酶变得不活跃 了。吸附于粘粒的有机分子在微生物分解作用中可 部分地受到保护。土壤中的有机质含量增加, 氮素 及磷素含量亦增加, 因为它们是有机质的重要组成 部分。”沟谷雨林土壤中有机质及养分的平衡值, 无 论是旱季结束时还是雨季结束时均大于低山雨林, 表明沟谷雨林土壤的粘土含量大于低山雨林。

西双版纳望天树雨林土壤的有机质含量, 总的 来说季节变化所导致的差异不明显, 地貌的不同所 导致的差异明显。在全年期间, 低山雨林的上下层 土壤有机质含量都极显著地小于沟谷雨林; 受有机 质分解释放养分的直接影响, 土壤的全氮含量, 同样 也具有极显著的差异; 低山雨林土壤的全磷和全钾 含量, 在旱季结束时极显著地小于沟谷雨林, 雨季结 束时, 差异增大, 变成极显著地小于沟谷雨林。表明 沟谷雨林土壤养分平衡值高于低山雨林, 低山雨林 土壤养分受雨季的影响, 减少的幅度大于沟谷雨林。 从两个季节土壤养分的对比可以看出, 不论是沟谷 雨林, 还是低山雨林, 大部分养分的动态变化趋势几 乎是一致的。

3)磷素的缺乏是西双版纳望天树群落林地土壤 肥力的主要限制性因素之一，土壤下层 $(10 \sim 25 \mathrm{~cm})$ 的有效性磷，长期处于严重贫痊 (小于 $5 \mathrm{mg} \mathrm{kg}^{-1}$ ) 的状况，土壤中磷素含量，地表始终大于下层，说明 调落物释放出的磷对植物的吸收极其重要。Bear (1964) 认为 土壤的表层常常有丰富的磷, 是被根 吸收, 通过枯枝落叶转到表层, 并且大部分土壤磷是 有机态的。”Foth (1978) 认为 但是强度风化的磷 质, 在土壤 $\mathrm{pH}$ 值为 $4.5 \sim 4.8$ 之间，磷素很快被土壤 固定, 主要形成铁-磷和闭蓄态磷 (占全磷含量的 $70 \% ８ 5 \%$ ），溶液中只能维持极低的平衡浓度，表 土溶液中的磷在下渗的过程中很快被固定。植被要 吸取磷素就要吸收极大比例的水分，因为磷从土壤 粘粒表面扩散到水膜里并迁移到达植物根部的速度 与浓度取决于土壤水分。”西双版纳望天树群落林 地植物吸收土壤中的磷量, 对土壤水分状况及植被 蒸腾量的依赖性很强。沟谷雨林和低山雨林土壤含
水量 , 3 月平均为 $17.07 \%$ 与 $18.85 \%$; 月平均为 $25.31 \%$ 与 $28.62 \% ; 11$ 月平均为 $25.99 \%$ 与 $30.36 \%$ 土壤深层 $1 \mathrm{~m}$ 以下含水量终年保持在 $22 \%$ ～29\%之间,在有效性水分较高的情况下, 全年土 壤不缺水。很明显地表明, 植被的蒸腾量差异和土 壤粘粒的多少, 都直接影响着根系对土壤水分和养 分的吸收, 因此低山雨林土壤有效态磷大约为沟谷 雨林的一半。全磷的含量低山雨林上层土壤在旱季 结束与雨季结束时分别为 $0.0384 \%$ 和 $0.0352 \%$, 沟谷雨林为 $0.048 \%$ 和 $0.0457 \%$, 表明低山雨林磷 的减少量大于沟谷雨林, 其矿化程度和生物循环速 度更强烈、更快。根据德国化学家李比西的最小因 子定律的原理(骆世明等, 1987) , 有效性磷的缺乏是 植被吸收养分的主要障碍因子。

4) 望天树雨林土壤养分含量的季节性变化受到 水热条件的影响很大。在本研究中, 不论是在沟谷 内, 还是位于低山地区的望天树雨林, 土壤中各养分 的季节性动态变化趋势相同, 变化的幅度为低山雨 林大于沟谷雨林, 养分的全含量和有效态的含量经 过雨季均有不同程度的减少, 这与鼎湖山林地在雨 季期间土壤的养分含量增加的规律相反(夏汉平等， 1997) 其主要原因是旱季, 鼎湖山的森林小气候 为“: $1 \sim 3$ 月和 $10 \sim 12$ 月低温干燥, 土壤微生物活性 低，有机质分解慢(张德强等，2000），西双版纳望天 树雨林的小气候则是低温潮湿, 3、4 月进入干热季 节。但是土壤养分的季节变化的原理是类似的，以 磷素为例 根据西双版纳的气候特点, 12 2 月为冬 季(张克映,1963) ,由于低温潮湿, 有机物难以矿化, 土壤磷素的活化比较困难, 而且这时的微生物将相 当的磷素固定。3 5 月, 由于干热的旱季水分协 迫, 造成雨林的调落物高峰期, 此时“, 耐旱的放线菌 增加, 降解调落物中较难分解的成分 (张萍, 1995) ,"干旱期间微生物继续生长并积累营养 (潘 超美等，2000）”,壤中的全磷与有效性的磷均有不 同程度的增加。当 5 月下旬，雨水明显增加“, 进入 雨季后, 气温较高, 大量细菌繁殖, 达到全年的最多 数量时, 加速了分解凋落物中较简单易分解的成分 (张萍, 1995)” 部分被固定的磷得以释放,加之微生 物的更新换代, 部分微生物中的磷也被矿化, 但是这 一时期, 生长旺盛的植物要从土壤中吸取大量的养 分。有效态磷的平衡值, 是植物从土壤中吸收的磷 与由土壤、微生物和凋落物中释放出有效态磷的差 额，同时也受到土壤粘粒的吸附作用的影响，形成平 衡值的大小不等情况。雨季结束, 气温下降, 在望天 
树群落的顶极雨林内, 土壤养分含量变化又开始了 新的一个周期。

\section{4 结 论}

西双版纳望天树群落生境位于其适宜生存环境 的最北缘, 土壤水热条件变化易受地形和气候特点 的影响，土壤的养分含量差异幅度较大, 差异最大的 为有效性磷, 可以达到 $50 \%$ 左右, 沟谷雨林土壤中 养分富集程度大于低山雨林。望天树土壤养分的消 耗量雨季大于旱季, 有机物的矿化是有效养分的重 要来源之一, 造成表土层 $(0 \sim 10 \mathrm{~cm})$ 与下层 $(10 \sim$ $25 \mathrm{~cm})$ 土壤的养分差异极为明显, 因此地表的肥力 是十分宝贵的。

位于低山的望天树雨林土壤养分在雨季期间消 耗量大于沟谷雨林, 经对比检验, 雨季结束后, 土壤 中的全磷、全钾和有效性氮比旱季结束时差异扩大。 有效性磷的差异减小是因为含量过低, 同时也表明 全磷经矿化释放出的有效性磷, 相对而言仍然是供 给不足。有效性钾在土壤中分布均匀而且差异不明 显取决于本身的化学性质活泼和适度的水热条件。

磷素在土壤中的稳定性和有效态磷素的缺乏是 西双版纳望天树群落林地土壤肥力的主要限制性因 素之一植物为了吸收更多的磷素,一方面把根扎得 更深, 从深处吸收母质风化释放出的磷, 另一方面扩 大地表根系与土壤的接触面积吸取有机物释放出的 磷和其它养分。在旱季的干热期 地表水分的减少, 使土壤深层的根系吸收更加重要, 由于幼苗、幼树的 根系短浅, 使其生长发育在旱季受到较大的影响。

\section{参 考 文 献}

Bear , F. E. 1964. Chemistry of the soil. New York: Rcinhod Press. 233, 240, 245.

Foth, H. D. 1978. Fundamentals of soil science. New York: John Wiley \& Sons, Inc. $127 \sim 129,207,224,312 \sim 316,330 \sim$ 333.

He, Y. Q. (何园球), Q. G. Zhao (赵其国)， M. Z. Wang (王明珠) \& H.Shi (石华). 1993. Research on characteristics of nutrient cycling and soil-forming process of forest soils in tropics and subtropics of China. Soils (土壤), 25: $292 \sim 298$. (in Chinese with English abstract)

Liu, W. J. (刘文杰), Q. J. Li (李庆军), G. M. Zhang (张光 明), J. P. Shi (施济普) \& K. J. Bai (白坤甲). 2000. Microclimatic characteristics of canopy gaps in Shorea chinensis forestn in Xishuangbanna. Acta Phytoecologica Sinica (植物生 态学报), 24: 356 361. (in Chinese with English abstract)
Luo, S. M. (骆世明), L. H. Chen (陈华) \& F . Yan (严斧). 1978. Agroecology. Changsha: Hunan Academic Press. 149. (in Chinese)

Niu, W. Y. (牛文元). 1981. Physical geography. Beijing: Science Press. 198. (in Chinese)

Pan, C. M. (潘超美) , F . Yang (杨风), H. S. Zheng (郑海 水), Z. J. Yang (杨曾奖) \& Y. J. Li (李幼菊)。2000. Study on soil microbial biomass in rubber plantation intercropping with Amomum villosum or Coffea arabica. Soil and Environmental Sciences (土壤与环境科学), 9: $114 \sim 116$. (in Chinese with English abstract)

Sun, B. (孙波), T. L. Zhang (张桃林) \& Q. G. Zhao (赵其 国). 1995. Integrated evaluation of in poverishment of soil nutrients in red earth hilly regions in south China. Soils (土壤), 27: $119 \sim 128$. (in Chinese with English abstract)

Xia，H. P. (夏汉平)，Q．F. Yu (余清发) \& D. Q. Zhang (张德强). 1997. The soil acidity and nutrient contents, and their characteristics of seasonal dynamic of Dinghushan Nature Reserve. Acta Ecologica Sinica (生态学报), 17: 645 653. (in Chinese with English abstract)

Ying, S. H. (殷寿华) \& J. G. Shuai (帅建国). 1990. Study on fruiting behaviour, seedling establishment and population age classes of Parashorea chinensis. Acta Botanica Yunnanica (云南 植物研究), 12:415 420. (in Chinese with English abstract)

Zang, D.Q. (张德强), W H. Ye (叶万辉), Q. F. Yu (余清 发), G. H. Kong (孔国辉) \& Y. C. Zhang (张佑倡). 2000. The litter-fall of representative forests of successional series in Dinghushan. Acta Ecologica Sinica (生态学报), 20: 938 944. (in Chinese with English abstract)

Zhang, K. Y. (张克映) . 1963. An analysis on the characteristics and forming factors of climate in the south part of Yunnan. Acta Meteorologica Sinica (气象学报), 33: 210 230. (in Chinese with English abstract)

Zhang, P. (张萍). 1995. Ecological distribution and biochemical properties of soil microorganisms in secondary forests in Xishuangbanna. Chinese Journal of Ecology (生态学杂志), 14: 21 26. (in Chinese with English abstract)

Zhao, Q. G. (赵其国), M. Z. Wang (王明珠) \& Y. Q. He (何园球). 1991. Forest litter and its effect on soil in tropical and subtropical China. Soils (土壤), 23: 8 15. (in Chinese)

Zhao, X. N. (赵学农), M. Cao (曹敏) \& A. J. He (和爱 军). 1990. A preliminary study on the dynamics of parashorea chinensis population in Xishuangbanna region, Yunnan. Acta Botanica Yunnanica (云南植物研究) , 12: $405 \sim 414$. (in Chinese with English abstract)

Zheng, Z. (郑征), L. H. Liu (刘伦辉), A.J. He (和爱军), G. F. Jing (荆桂芬) \& G.W. Liu (刘国武). 1990. Litterfall and leaf consumption by animals in humid seasonal rainforest in Xishuangbanna, China. Acta Botanica Sinica (植物学报), 32: $551 \sim 557$. (in Chinese with English abstract)

Zheng, Z. (郑征), Z. L.Feng (冯志立), M. Cao (曹敏), H. M. Liu (刘宏茂) \& L. H. Liu (刘伦辉). 2000. Biomass and net primary production of primary tropical wet seasonal rainforest in Xishuangbanna. Acta Phytoecologica Sinica (植物生态学 报), 24: $197 \sim 203$. (in Chinese with English abstract)

Zhu, H. (朱华). 1992. Research of community ecology on Shorea chinensis forest in Xishuangbanna. Acta Botanica Yunnanica (云南植物研究), 14: $210 \sim 230$. (in Chinese with English abstract) 